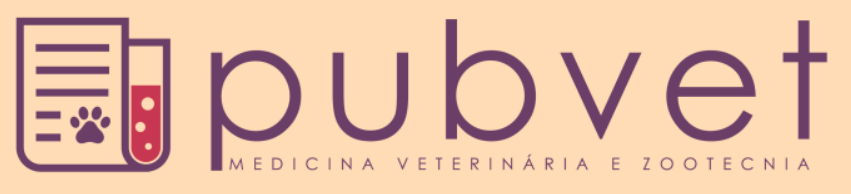

https://doi.org/10.31533/pubvet.v12n9a166.1-5

\title{
Mastocitoma de alto grau em um cão: relato de caso
}

\author{
Lourival Barros de Sousa Brito Pereira ${ }^{1} \bullet$, Homero Firmo Pessoa ${ }^{2}$, Lucilo Bioni da \\ Fonseca Filho $^{30}$, Natália Cyntia Alves Medeiros ${ }^{4}$, Melissa Barbosa Pontes ${ }^{5}{ }^{\circ}$, Nicolli \\ de Albuquerque Leal Gomes D'Alcantara ${ }^{6}{ }^{\bullet}$, Jordy Diniz de Oliveira Lima ${ }^{7}{ }^{\bullet}$, Gabriella \\ Mignac Mendonça Wanderley ${ }^{8}{ }^{\ominus}$, Júlio Cézar dos Santos Nascimento ${ }^{9} \bullet$
}

\author{
${ }^{1}$ Médico veterinário. Recife-PE Brasil.E-mail: lorinho2013.1@ @otmail.com \\ ${ }^{2}$ Médico veterinário. Recife-PE Brasil. E-mail: hfpessoa@hotmail.com \\ ${ }^{3}$ Médico veterinário. Recife-PE Brasil.E-mail: lucilofilho@gmail.com \\ ${ }^{4}$ Discente do curso de Medicina Veterinária em Centro Universitário Mauricio de Nassau. Recife-PE Brasil. E-mail: contato.nataliacvntia@ hotmail.comm \\ ${ }^{5}$ Discente em do curso de Medicina Veterinária em Centro Universitário Brasileiro. Recife-PE Brasil. E-mail: melissa.pontes@gmail.com \\ ${ }^{6}$ Discente do curso de Medicina Veterinária em Centro Universitário Mauricio de Nassau. Recife-PE Brasil. E-mail: nicollileal@hotmail.com \\ ${ }^{7}$ Discente do curso de Medicina Veterinária em Centro Universitário Mauricio de Nassau. Recife-PE Brasil.E-mail: jordydiniz@hotmail.com \\ ${ }^{8}$ Discente do curso de Medicina Veterinária em Centro Universitário Mauricio de Nassau. Recife-PE Brasil.E-mail: gbimignacmewz@hotmail.com \\ ${ }^{9}$ Professor em Centro Universitário Mauricio de Nassau, área de Medicina Veterinária. Recife-PE Brasil. E-mail:juliozootecnista@hotmail.com
}

RESUMO. O mastocitoma é um dos tumores malignos mais diagnosticados em cães. Sua apresentação cutânea é mais frequente, principalmente na derme e tecido subcutâneo, mais pode ocorrer também em conjuntiva, glândula salivar, nasofaringe, laringe, cavidade oral, trato gastrointestinal e coluna. Esta neoplasia tem um comportamento biológico variado e imprevisível, podendo apresentar desde um único nódulo de comportamento benigno até múltiplos nódulos metastáticos. Dentre todas as formas de graduar o mastocitoma, a que proporciona elevado nível de concordância é a classificação em baixo e alto grau. Para diagnóstico definitivo e melhor conduta terapêutica, se faz necessário à realização do exame histopatológico. O tratamento para o mastocitoma, vai depender da classificação histopatológica e o estadiamento clínico. A excisão cirúrgica é indicada para todos os mastocitomas e devem ter margens de segurança de no mínimo $3 \mathrm{~cm}$. A quimioterapia é indicada para mastocitomas grau II, III ou alto grau e pode ser empregada com o objetivo de cito-redução ou como adjuvante à cirurgia. O prognóstico vai depender da localização, número de tumor e presença de ulceração. Objetivou-se com este trabalho, relatar um caso de mastocitoma de alto grau em um cão, da raça Pug, com três anos de idade com ênfase nos achados histopatológicos e conduta terapêutica.

Palavras chave: cirurgia, quimioterapia, neoplasia

\section{High-grade mastocytoma in a dog: case report}

ABSTRACT. Mastocytoma is one of the most malignant tumors diagnosed in dogs. Its cutaneous presentation is more frequent, especially in skin and subcutaneous tissue, more or less conjunctiva, salivary gland, nasopharynx, larynx, oral cavity, gastrointestinal tract and spine. This neoplasm has a varied and unpredictable biological code, and may present a single nodule of benign behavior up to multiple metastatic nodules. Among all forms of mastocytoma graduation, the high level of agreement is a low and high grade classification. For the definitive diagnosis and the best therapeutic conduction, the accomplishment of the histopathological examination. The treatment for the mastocytoma, will enter into the histopathological and the american medical clinic. Surgical excision is indicated for all mast cells and should be at least $3 \mathrm{~cm}$ in safety markings. Chemotherapy is indicated for grade II, III or high grade mastocytomas and may be used for the purpose of quit-reduction or as an adjunct to surgery. The prognosis will depend on the location, tumor number and 
presence of ulceration. The objective of this work was to report a case of high-grade mastocytoma in a dog, the history of a man with a human anatomy problem, with emphasis on histopathological findings and therapeutic conduction.

Keywords: surgery, chemotherapy, neoplasm

\section{Mastocitoma de alto grado en un perro: relato de caso}

RESUMEN. El mastocitoma es uno de los tumores malignos más diagnosticados en perros. Su presentación cutánea es frecuente, principalmente en la dermis y tejido subcutáneo, más puede presentarse también en conjuntiva, glándula salivar, nasofaringe, laringe, cavidad oral, tracto gastrointestinal y columna. Esta neoplasia tiene un comportamiento biológico variado e imprevisible, pudiendo presentar desde un único nódulo de comportamiento benigno hasta múltiples nódulos metastáticos. Entre todas las formas de graduar el mastocitoma, la que proporciona un alto nivel de concordancia es la clasificación a bajo y alto grado. Para diagnóstico definitivo y mejor conducta terapéutica, se hace necesario la realización del examen histopatológico. El tratamiento para el mastocitoma, dependerá de la clasificación histopatológica y la estadificación clínica. La excisión quirúrgica es indicada para todos los mastocitomas y deben tener marchas de seguridad de por lo menos $3 \mathrm{~cm}$. La quimioterapia es indicada para mastocitomas grado II, III o alto grado y puede ser empleada con el objetivo de cito-reducción o como adyuvante a la cirugía. El pronóstico dependerá de la ubicación, el número de tumor y la presencia de ulceración. Se objetivó con este trabajo, relatar un caso de mastocitoma de alto grado en un perro, de la raza Pug, con tres años de edad con énfasis en los hallazgos histopatológicos y conducta terapéutica.

Palabras clave: cirugía, quimioterapia, neoplasia

\section{Introdução}

Tumores de pele é a segunda neoplasia que mais acomete cães, sendo o tumor de mama o primeiro (Braz et al., 2017). O mastocitoma é um neoplasma maligno mais diagnosticado em cães e a sua apresentação cutânea é de aproximadamente $11 \%$ (Melo et al., 2013). Este tipo de tumor vem crescendo nos últimos anos, tornando-se o principal fator de morte nos cães (Prado et al., 2012). Define-se mastocitoma como uma proliferação neoplásica de mastócitos, conhecida também como mastocitoma histiocítico sarcoma da célula do mastócito (Natividade et al., 2014). Pertence ao grupo de neoplasmas conhecidos como tumores de células redondas, juntamente com linfoma, histiocitomas e tumor venéreo transmissível (Palma et al., 2009).

O comportamento biológico do mastocitoma é variado e imprevisível, podendo apresentar nodulação única com comportamento benigno até múltiplas nodulações e metastáticas com comportamento extremamente maligno (Natividade et al., 2014). Sua apresentação pode ser granulomatosa ou ulcerativa, podendo ser avermelhado e apresentar prurido (Braz et al., 2017). Nos cães, os neoplasmas relacionados com os mastócitos geralmente ocorrem na região posterior do corpo do animal, sendo a bolsa escrotal e o flanco locais de maior incidência. $\mathrm{Na}$ maioria dos casos apresentam-se como uma massa cutânea com cerca de 2 a $5 \mathrm{~cm}$ de diâmetro e altura de $1 \mathrm{a} 3 \mathrm{~cm}$, sendo associados com prurido, edema, eritema e úlceras na região tumoral (Prado et al., 2012). O mastocitoma tem uma etiopatogenia multifatorial, porém sabe-se que animais da raça braquiocefálicas são mais acometidos (Palma et al., 2009), mas podem ocorrer em qualquer raça como Boxer, Boston Terrier, Bullmastiff, Bulldog,Setter Inglês, Labrador, Golden Retriever, Teckel, Weimaraner (Braz et al., 2017), Fox Terrier, Beagle, Schunauzer, Cocker Spaniel, Pit Bull Terrier e Sharpei . A idade media de animais acometido por essa neoplasia é de oito a nove anos ( Santos et al., 2010).

Os mastócitos neoplásicos apresentam granulações citoplasmáticas como heparina e histamina. Muitas vezes, estas substâncias podem estar aumentadas e quando liberadas podem causar graves efeitos sistêmicos como ulceração gastrointestinal, hemorragias, inchaço, prurido, vômitos, diarreia e em casos raros choque e colapso (Prado et al., 2012). O diagnóstico do mastocitoma é baseado no exame citopatológico e/ou exame histopatológico das lesões. O exame citopatológico é o método mais simples para diagnóstico e o histopatológico é mais indicado para classificar o grau de malignidade. A imuno- 
histoquimica é outro recurso que pode ser usado no diagnostico deste neoplasma (Palma et al., 2009). Os mastócitos normais apresentam-se como células de fácil identificação, são redondas, seu núcleo vai de redondo a oval, a célula apresenta tamanho variado e geralmente, excêntrico (Palma et al., 2009). Existem vários métodos para graduação do mastocitoma e isto faz com que quando uma mesma amostra é analisada por diferentes observadores podem ocorrer discordância, por isso Kiupel et al. (2011) propuseram uma classificação que divide $\mathrm{o}$ mastocitoma em baixo grau e alto grau de malignidade (Melo et al., 2013).

O exame histopatológico tem influência direta na conduta terapêutica, que depende do grau de diferenciação, intensidade de proliferação e envolvimento de margem cirúrgica. A ressecção cirúrgica é a modalidade de tratamento mais efetiva, desde que realizada com margens de segurança (Prado et al., 2009; Melo et al., 2013). A quimioterapia geralmente é indicada para tumores de alto grau, disseminados e em tumores não operáveis (Prado et al., 2012). Os fármacos comumente utilizados no tratamento desta neoplasia são vimblastina, prednisona, ciclofosfamida e lomustina (Melo et al., 2013) A quimioterapia com glicocorticoides resulta frequentemente em remissões parcial ou completa deste neoplasma. A radioterapia tem um papel importante no tratamento do mastocitoma porém é restrito a alguns centros de referências (Palma et al., 2009). O prognostico depende da localização do neoplasma, número de tumores e presença de úlceras. Os mastocitomas que se desenvolvem no leito ungueal, escroto, prepúcio e focinho são mais agressivos e geram um tempo de sobrevida mais curto (Melo et al., 2013).

\section{Material e métodos}

Um cão da raça Pug, macho, com três anos de idade foi atendido em uma clinica veterinária com histórico de caroço vermelho no lábio superior com evolução há 1 mês e com bastante prurido. Animal era vacinado, tinha dieta a base de ração super premium e sua rotina era dentro do apartamento. Ao exame físico foi constatado nódulo em lábio superior com $4 \mathrm{~cm}$ de diâmetro (Figura 1), hiperêmico e firme. Foram solicitados exames de rotina e exame histopatológico, por meio da técnica de biópsia incisional, com o objetivo de obter diagnostico definitivo e para uma possível graduação do tumor. Após diagnóstico de mastocitoma grau II, foi realizada quimioterapia com a finalidade de citorredução do nódulo, para garantir margem de segurança na hora da excisão cirúrgica. O nódulo foi fixado em formol a $10 \%$ para realizar um novo exame histopatológico com o intuito de verificar o comprometimento de margens cirúrgicas. Pós cirurgico o animal foi submetido a sessões de quimioterapia e depois o tutor foi orientado a retornar à clínica para reavaliação a cada 3 meses.

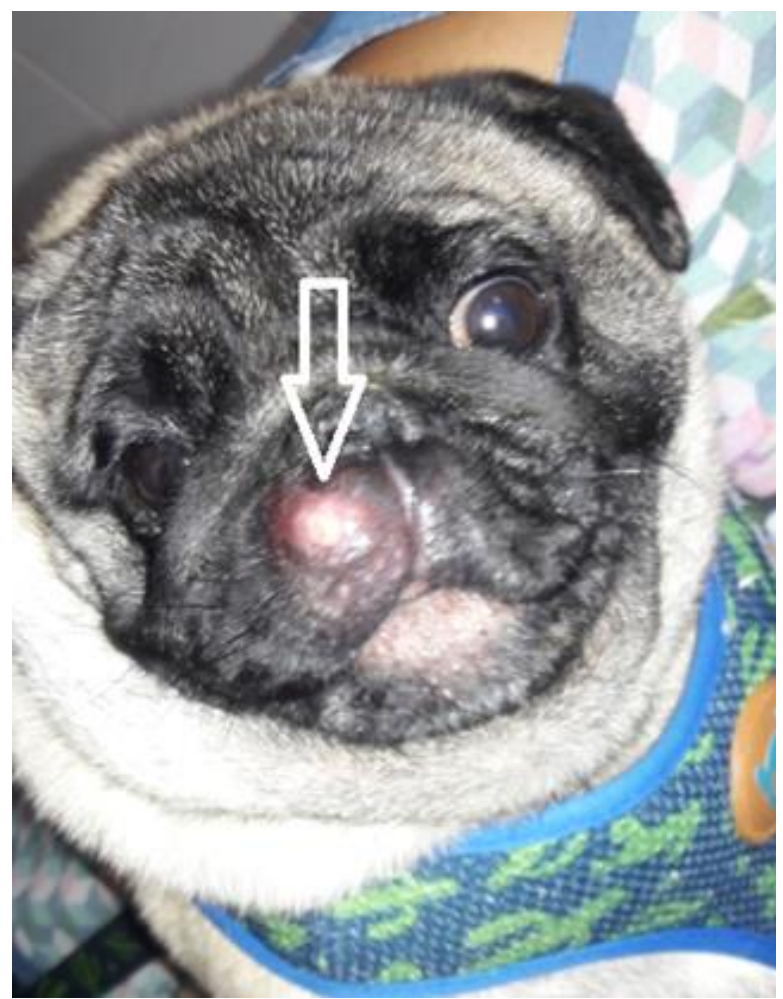

Figura 1. Foto demonstrativa do nódulo em lábio superior.

\section{Resultados}

No primeiro exame histopatológico, através da biopsia incisional, se obteve o diagnóstico definitivo, de mastocitoma grau II. Nas lâminas histológicas foi visualizado neoplasia de células redondas, pobremente delimitadas, não encapsuladas, infiltrativa, disposta em padrão cordões, sustentadas por delgado tecido fibrovascular. As células neoplásicas apresentavam citoplasma amplo, eosinofílico, de limites bem definidos e contendo moderada a acentuada granulação basofilica. Os núcleos eram redondos a ovalados, com cromatina frouxa e um a dois nucléolos evidentes. Havia anisocitose e anisocariose moderadas e pleomorfismo celular e nuclear moderado. Foram observados duas figuras de mitoses em 10 campos na objetiva de 40x. Concluindo ser mastocitoma grau II.

Após o diagnóstico de mastocitoma grau II, o paciente foi submetido à quimioterapia com a 
finalidade de citorredução do nódulo. O protocolo instituído foi vimblastina $2 \mathrm{mg} / \mathrm{m}^{2}$ e prednisolona $1 \mathrm{mg} / \mathrm{kg}$, uma vez dia por 2 semanas e em seguida $0,5 \mathrm{mg} / \mathrm{kg}$. Foram feitas quatro sessões de vimblastina com intervalo de quinze dias entre elas. Ao final da quarta sessão de quimioterapia, o tumor estava com $1,15 \mathrm{~cm}$ (Figura 2) de diâmetro e foi realizado exames pré operatórios para exérese cirúrgica com margem de segurança.

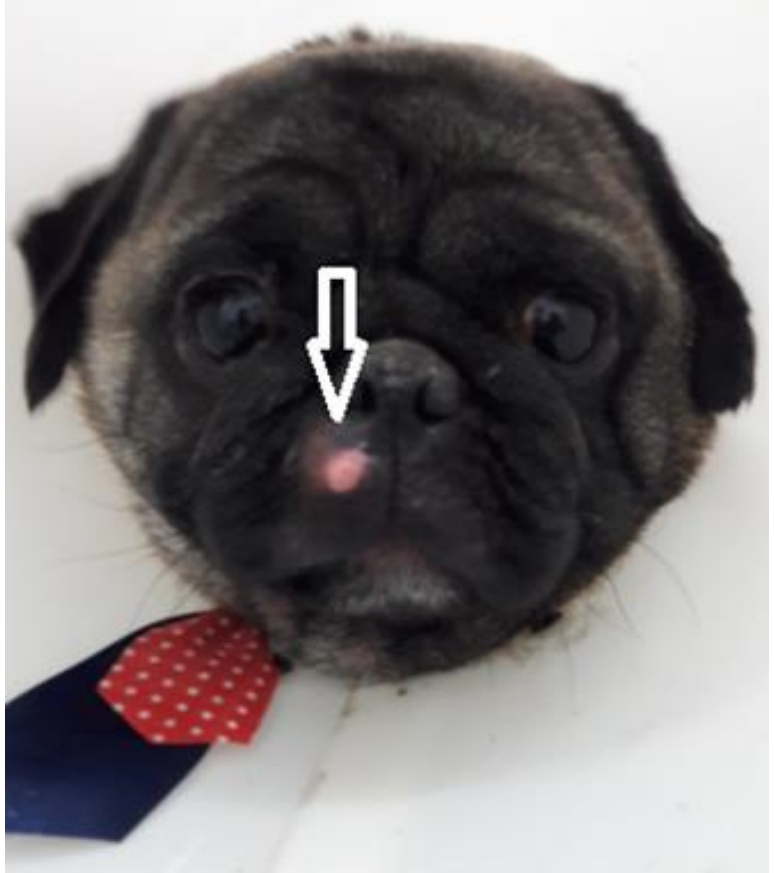

Figura 2. Foto demonstrativa do nódulo em lábio superior com 1,15 de diâmetro.

Foi realizado o procedimento cirurgico para exérese do nódulo e do linfonodo submandibular, fixados em formol a $10 \%$ e realizado o exame histopatológico com a finalidade de ter informação sobre as margens cirúrgica e infiltrado neoplasia em linfonodo. Nos achados histopatológicos havia presença de proliferação nodular neoplásica em porção cutânea, acometendo derme superficial e profunda, infiltrando-se em tecido muscular esquelético. A neoplasia consistia em proliferação de mastócitos, de moderada densidade celular, arranjados em cordões e pacotes, em meio a moderado estroma colagenoso. Os mastócitos exibiam núcleos arredondados, com moderada anisocariose e citoplasma em moderada quantidade arroxeado granular. Foi observado 1 mitose em 10 campos de 400x. As margens estavam livres de células neoplásicas. Nos achados do exame histopatológico do linfonodo foi visto que a arquitetura estava preservada, com presença de áreas multifocais de infiltrado micronodular de seios nodais e parêquima nodal por infiltrado de mastócitos moderadamente diferenciados concluindo ser uma metástase de mastocitoma moderadamente diferenciado.

Retirados os pontos da cirurgia, o animal foi submetido à mais quatro sessões de quimioterapia com vimblastina $2,5 \mathrm{mg} / \mathrm{m}^{2}$ a cada quinze dias, predinisolona $1 \mathrm{mg} / \mathrm{kg}$ por duas semanas, ômega 3 e omeprazol em jejum pela manhã. Foi feito primeira reavaliação depois de 3 meses da última sessão de quimioterapia e estava sem sinal de recidiva ou novos nódulos (Figura 3).

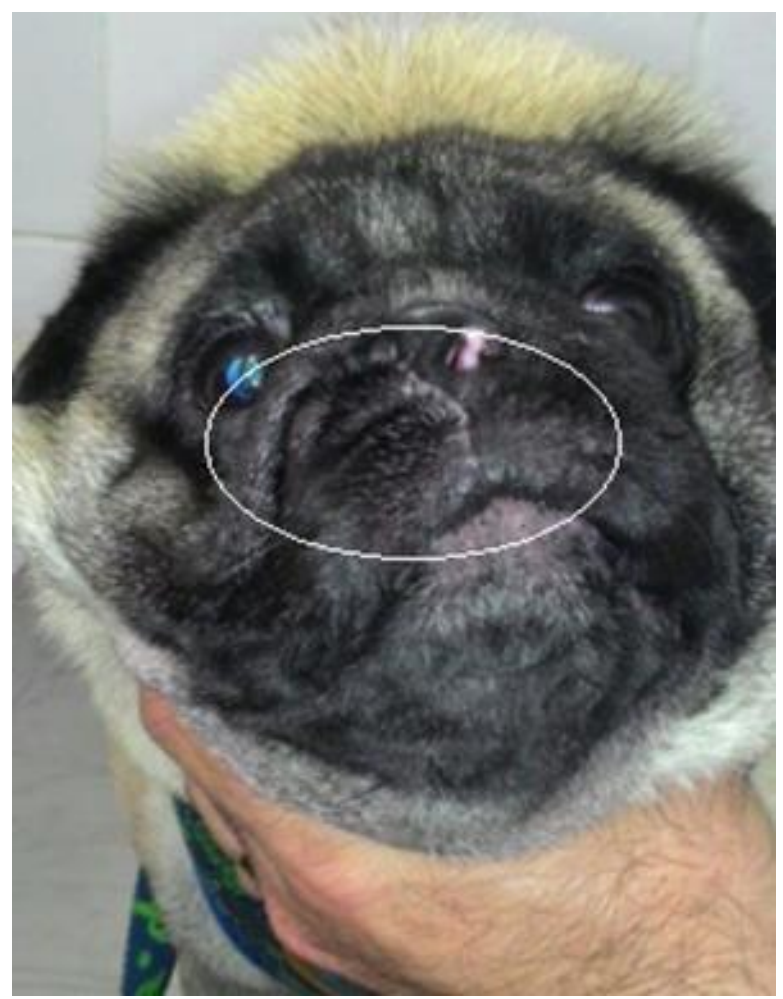

Figura 3. Foto demonstrativa da região após procedimento cirúrgico e sessão de quimioterapia.

\section{Discussão}

O animal do presente trabalho era da raça Pug, que segundo a literatura os animais braquicefálicas são as mais predispostas, porém a idade média de animais diagnosticados com mastocitoma é de oito anos o que não corrobora com o apresentado no animal do presente relato que tinha três anos. Segundo a literatura o comportamento biológico do mastocitoma é variado e o que foi visto no animal do presente relato foi uma lesão única, firme em lábio superior com característica macroscópica de um furúnculo (Palma et al., 2009). Após o diagnóstico definitivo e graduação da neoplasia em mastocitoma grau II, por meio de biopsia incisional, foi realizado a 
quimioterapia para haver uma cito-redução do nódulo e assim fazer a excisão cirúrgica com ampla margem de segurança de no mínimo três centímetros. Inicialmente o nódulo estava com 4 $\mathrm{cm}$ de diâmetro e ao final da quarta sessão de quimioterapia o nódulo estava com $1,15 \mathrm{~cm}$ de diâmetro, já podendo intervir cirurgicamente para a excisão completa do nódulo e do linfonodo que drena a região tumoral.

O tratamento cirúrgico é considerado de eleição para todos mastocitomas (Crivellenti \& Borin, 2015). No laudo histopatológico por meio da biopsia excisional, as margens cirúrgicas estavam livres de células neoplásicas, porém havia um infiltrado no linfonodo submadibular, fazendo com que retornasse as sessões de quimioterapia com vimblastina $2,5 \mathrm{mg} / \mathrm{m}^{2}$ a cada 15 dias (Prado et al., 2009; Melo et al., 2013) e glicocorticoides.

$\mathrm{O}$ animal do presente relato retornou a clínica após 3 meses da última sessão de quimioterapia e o mesmo encontrava-se sem alteração clínica e sem sinal de recidiva ou novos nódulos.

\section{Conclusão}

O mastocitoma é uma neoplasia de células redondas maligna, que tem um comportamento biológico bastante variado e imprevisível. Para diagnóstico definitivo, graduação e auxilio na conduta terapêutica, é necessário a realização do exame histopatológico. A quimioterapia associado com glicocorticoide mostrou ser eficaz na terapia do mastocitoma associado à cirurgia, sendo o acompanhamento clínico periodico indispensável.

\section{Referências}

Braz, P. H., Haniu, A. E. C. J., Souza, A. I. \& Brum, K. B. 2017. Epidemiologia do mastocitoma em cães em uma região do Mato Grosso do Sul. PUBVET, 11, 1002-1007.

Crivellenti, L. Z. \& Borin-Crivellenti, S. 2015. Casos de rotina em medicina veterinária de pequenos animais ( $2^{\mathrm{a}}$ ed.). Editora MedVet, São Paulo, BR.

Kiupel, M., Webster, J. D., Bailey, K. L., Best, S., DeLay, J., Detrisac, C. J., Fitzgerald, S. D.,
Gamble, D., Ginn, P. E. \& Goldschmidt, M. H. 2011. Proposal of a 2-tier histologic grading system for canine cutaneous mast cell tumors to more accurately predict biological behavior. Veterinary Pathology, 48, 147-155.

Melo, I. H. S., Magalhães, G. M., Alves, C. E. F. \& Calazans, S. G. 2013. Mastocitoma cutâneo em cães: uma breve revisão. Revista de Educação Continuada em Medicina Veterinária e Zootecnia, 11, 38-43.

Natividade, F. S., Castro, M. B., Silva, A. S., Oliveira, L. B., McManus, C. M. \& Galera, P. D. 2014. Análise de sobrevida e fatores prognósticos de cães com mastocitoma cutâneo. Pesquisa Veterinária Brasileira, 34, 874-884.

Palma, H. E., Martins, D. B., Basso, P. C., Amaral, A. S., Texeira, L. V. \& Lopes, S. T. A. 2009. Mastocitoma cutâneo canino - Revisão. Revista Científica de Medicina Veterinaria Pequenos Animais e Animais de Estimação, 7, 523-528.

Prado, A. A. F., Leão, D. A., Ferreira, A. O., Machado, C. \& Maria, D. A. 2012. Mastocitoma em cães: aspectos clínicos, histopatológicos e tratamento. Enciclopédia Biosfera, Centro Científico Conhecer, 8, 2151.

Santos, L. M. Rocha, J. R., Merlini, G. P. \& Cabrini, T. M. 2010. Quimioterapia antineoplásica no tratamento de mastocitoma de bolsa escrotal em boxer- relato de caso. Revista Cientifica Eletrônica de Medicina Veterinária, Ano VIII (14) .

Recebido: 15 Julho, 2018.

Aprovado: 13 Agosto, 2018

Publicado: 3 Setembro, 2018

Licenciamento: Este artigo é publicado na modalidade Acesso Aberto sob a licença Creative Commons Atribuição 4.0 (CC-BY 4.0), a qual permite uso irrestrito, distribuição, reprodução em qualquer meio, desde que o autor e a fonte sejam devidamente creditados. 